\title{
Writing to learn via text chat: Task implementation and focus on form
}

\author{
Nik Aloesnita Nik Mohd Alwi ${ }^{a}$, Rebecca Adams ${ }^{\mathrm{b}}$, Jonathan Newton ${ }^{\mathrm{c}, *}$ \\ ${ }^{a}$ Centre for Modern Languages \& Human Sciences, Universiti Malaysia Pahang, Lebuhraya Tun Razak, \\ 26300 Kuantan, Pahang, Malaysia \\ ${ }^{\mathrm{b}}$ Department of Applied Language Studies and Linguistics, University of Auckland, PB 92019, \\ Auckland 1142, New Zealand \\ ${ }^{\mathrm{c}}$ School of Linguistics and Applied Language Studies (LALS), Victoria University of Wellington, \\ PO Box 600, Wellington 6140, New Zealand
}

\begin{abstract}
Research has shown that task-based computer-mediated communication (CMC) can foster attention to linguistic form in ways that may promote language learning (c.f., Blake, 2000; Smith, 2003, 2005). However, relatively little research has investigated how differences in the way that tasks are used in CMC settings influence learning opportunities during the task. In an attempt to shed light on the manner in which second language (L2) writing may contribute to L2 development, this chapter presents an empirical study of how two implementation features (degree of task structure and provision of language support) of a writing group task in simultaneous text-CMC influenced learner attention to linguistic form. The analysis draws on data from text chat performance and post-task group interviews to illustrate how aspects of task implementation in a technology-enhanced learning environment may promote attention to language expression and encourage collaborative work on language errors during writing task performance. (C) 2012 Elsevier Inc. All rights reserved.
\end{abstract}

Keywords: Task complexity; Computer-mediated communication; Focus-on-form; Cognition Hypothesis; Writing-to-learn the language

\section{Introduction}

Research and theory on the teaching and learning of an additional language (L2) indicates that writing can be viewed in two ways - either as a skill to be taught, learned, and assessed or as a 'means, context, and basis for learning both of language and of writing' (Cumming, 2011, p. viii). These orientations are conventionally distinguished as learning to write (LW) and writing to learn (WL). While LW is generally presented as a traditional, product-oriented writing instruction, WL traces its roots primarily to writing-across-the-curriculum educational reform (c.f., Ackerman, 1993). The cognitive premise of WL is that the act of engaging in writing develops thought, as Applebee asserts (1981), "at the point of utterance" (p. 10). From this perspective, writing is not only a tool for committing thought to paper, it is rather a means of mediating thought, in that it pushes learners to explore their thoughts and learn "from the act of writing itself what those thoughts are" (Zamel, 1982, p. 197), and gives to thoughts permanence they would not have in an unwritten state.

\footnotetext{
* Corresponding author. Tel.: +609 5493082; fax: +60 95493112.

E-mail addresses: aloesnita@ump.edu.my (N.A.N.M. Alwi), r.adams@auckland.ac.nz (R. Adams), jonathan.newton@vuw.ac.nz (J. Newton).
} 
While researchers of L1 writing have focused on how writing can promote learning across curricular areas, L2 researchers adopting a WL perspective have additionally considered the effect of writing on learning language. Manchón (2011) distinguishes these orientations as WLC (writing to learn content) and WLL (writing to learn language). The possibility that engaging in writing might be a particularly appropriate means of language learning was raised by Cumming (1990), who suggested that engaging in writing with a communicative orientation helps learners to make form-meaning connections, and to control and refine their knowledge of second language structures. In a comprehensive review of WLL studies, Manchón (2011) concluded that this body of research provides evidence that writing fosters linguistic processing that promotes learning; however, the way learner attention is directed to linguistic form may depend on learner variables as well as the type of writing task they engage in.

Relatively little research has investigated the WLL potential of writing carried out through computer-mediated communication (CMC). This is somewhat surprising since, as Warschauer (1998, p. 757) has suggested, to be proficient in an L2, a person must have the ability "to read, write and communicate in an electronic environment". To address this gap, the current study investigated writing in classroom language learning tasks via text-based synchronous computer-mediated communication (hereafter text chat). Specifically, it looked at how implementation features (degree of task structure and provision of language support) of a task performed via text chat influence the effectiveness of the task as a means of promoting learning opportunities. The study was motivated by recent research on the mediating effects of the cognitive complexity of tasks on learning opportunities in task-based language teaching (c.f., Robinson, 2001, 2005).

CMC can occur synchronously (SCMC) or asynchronously (ACMC). Research indicates that ACMC (e.g., bulletin board discussion) has advantages for learning to write because it allows time to compose and edit thoughts before making postings public and this leads to more thoughtful and better written work (Kim, Anderson, Nguyen-Jahiel, \& Archodidou, 2007; Shang, 2007). On the other hand, because SCMC (e.g., text chat) occurs in real-time, it allows participants to cocreate a text-discourse (Sanders, 2006). Opportunities to write collaboratively via SCMC offer a medium for learners to focus on language use and thus may provide a valuable vehicle for writing to learn the language (WLL).

SCMC can work in three different modes: text, audio, and video (Anderson \& Elloumi, 2004). However, technical constraints such as bandwidth limitations, network restrictions, and screen resolution compatibility make text SCMC (text chat) the most common, reliable, and affordable means of SCMC for educational purposes (González, 2003). Text chat is a hybrid of speech and writing (Herring, 1996; Yates, 1996). Like spoken language it involves rapid, spontaneous exchange of information in real time. But like writing it produces a relatively permanent record of the discourse, and incorporates punctuation and other writing devices. Text chat also has unique characteristics, including simplified register and syntax, abbreviations, and the use of symbols to express emotions (Smith, 2003). Researchers acknowledge the use of text chat as an effective medium for L2 learning and practice (Blake, 2005; Ortega, 2009; Smith, 2008). It is employed for practising language learning in various ways, including interacting with native speakers (Blake, 2005; Lee, 2004), developing intercultural understanding (Belz \& Müller-Hartmann, 2003; Ware \& Kramsch, 2005), conducting collaborative tasks (Newlands, Anderson, \& Mullin, 2003), and promoting autonomous learning (Emde, Schneider, \& Kötter, 2001).

To evaluate the potential of text chat for language acquisition, many previous studies have focused on opportunities for interaction in the second language afforded through this medium. Results from these studies show that interaction between NSs and NNSs via text chat promotes L2 learning (Blake, 2007; Lee, 2004). One advantage of text chat over oral, face-to-face interaction which may account for these findings is that noticing is more likely because the written modality of text chat allows learners the opportunity to re-read information by scrolling the messages backward and forward (Sauro, 2009; Sotillo, 2005). Thus interlocutors can continually "refresh memory traces" (Payne \& Whitney, 2002, p. 14) and focus and reflect on their output. According to Meskill (2005, p. 48), "computer screens can serve to anchor attention to forms..." with this visual saliency of language forms offering more opportunities for deeper processing of language forms, especially problematic forms.

While these claims are well supported by research (c.f., González-Lloret, 2009; Pellettieri, 2000; Shekary \& Tahririan, 2006), it is not simply the technology, but the design and use of appropriate tasks via the technology that is likely to maximise WLL opportunities. Prior research has shown that tasks can be designed to elicit language output in ways that promote L2 learning and development. Aspects of language production, including noticing and discussion of form, can be promoted through careful design and implementation of tasks (Robinson, 2001). While the studies discussed above show text chat to be a powerful site for learning, little is known about how the use of tasks in text chat can influence noticing, discussion, and, ultimately, learning of forms. 


\section{Tasks and language learning}

Task-based language teaching is based on the premise that language learning can occur analytically through holistic language use activities (Samuda \& Bygate, 2008) which should reflect the things learners need to be able to do beyond the classroom (Long \& Crookes, 1992). The large body of research on tasks has indicated that they may also promote the development of linguistic and cognitive skills (c.f., Van den Branden, Bygate, \& Norris, 2009).

Ellis (2003) defines tasks as pedagogical workplans with a primary focus on meaning, involving real-world processes of language use that engage cognitive processes to reach a clearly defined communicative outcome. While a large body of research has examined oral interactive tasks, and found strong evidence that these can promote noticing of language forms and learning (Hardy \& Moore, 2004; Michel, Kuiken, \& Vedder, 2007), relatively little research has examined the role of writing tasks in promoting language learning (but see contributions in Manchón, 2011). Some trends in this research include evidence of the effectiveness of feedback cycles in writing tasks in promoting learning of forms (Ishii, 2008; Swain \& Lapkin, 2001), differences among learner roles in collaborative writing tasks (Storch, 2003), and evidence that engagement in collaborative writing has positive effects for learning on both the quantity and quality of learner attention to language (Adams, 2006; Adams \& Ross-Feldman, 2008). Research on task-based writing therefore points to the benefits of this approach not just for learning to write, but also for learning second language forms in the context of writing engagement.

Research on second language learning through tasks has often focused on learner attention to form (Adams, 2003; Klapper \& Reese, 2003; Niu, 2009). During collaborative tasks, learners take opportunities to momentarily shift their focus from the expression of meaning to the way that meaning is encoded (Williams, 2001). Observable instances of attention to form have been labelled language-related episodes (LREs), defined by Swain and Lapkin (2001, p. 104) as "any part of a dialogue where students talk about language they are producing, question their language use, or other- or self-correct their language production". Research on interactions between learners has indicated that attending to form in interaction through LREs is strongly related to retention and future use of second language forms (Adams, 2007; Williams, 2001). For example, Leeser (2004) investigated the extent to which performing collaborative tasks pushed learners to reflect on their language use, finding frequent occurrence of LREs in learner-learner discourse. This study also signaled that task implementation conditions, specifically the inclusion of language support prior to task engagement, may have encouraged learners to focus on grammatical items. Similarly, Fortune (2005) found that learners focused more on grammar when they were familiarized with the use of a linguistic target prior to the task performance.

\section{Task complexity and language learning}

A substantial body of research has investigated how cognitive demands of tasks may increase or decrease the complexity of the task, which may in turn lead to different outcomes for learner language production (Foster \& Skehan, 1996; Gilabert, 2007; Kormos, 2011; Kuiken \& Vedder, 2008; Ong \& Zhang, 2010; Skehan \& Foster, 1997; Tavakoli \& Skehan, 2005; Yuan \& Ellis, 2003). Typically, these studies have investigated the effect of task complexity on fluency, accuracy, and complexity of L2 production. However, a growing body of research has also investigated the role of task complexity on attention to form (often measured through interactional modifications) during the completion of interactive tasks (Nuevo, 2006; Nuevo, Adams, \& Ross-Feldman, 2011; Révész, 2009).

Research on task complexity has been influenced by two competing theories: Skehan's (1998) trade-off effects proposal, which is based on the Limited Attentional Capacity Model, and Robinson's (2001, 2005) Cognition Hypothesis. Both of these theories of task complexity are based on the premise that manipulating task features can influence how learners allocate attentional resources, resulting in different outcomes for language production. The Cognition Hypothesis proposed by Robinson $(2001,2005)$ makes explicit predictions about the role of task complexity and learner focus on form. Different dimensions of complexity are developed in the Triadic Componential Framework for task design (Robinson, 2007b). The framework separates three factors: task complexity, task condition, and task difficulty, which influence task performance. Task complexity (the focus here) deals with the intrinsic, cognitive complexity of task features. These are divided into two categories: resource-directing and resource-dispersing; however, for both types of complexity, Robinson (2007a) predicts that increasing the complexity of interactive tasks will lead to the production of more interactional modifications such as LREs. 
Robinson (2001) has suggested that more studies be conducted to investigate the effects of interactive tasks along resource-dispersing (e.g., +/- planning time, $+/$ - prior knowledge) variables on learner language production. To date, most task complexity research has focused on the effect of increasing complexity along resource-directing (e.g., +/few elements, +/- reasoning demands) variables in monologic (Gilabert, 2007; Kormos, 2011; Kuiken \& Vedder, 2007; Tavakoli \& Foster, 2008) and interactive tasks (Nuevo, 2006; Nuevo et al., 2011; Révész, 2009; Robinson, 2001). While several studies have examined the effects of resource-dispersing variables on the fluency, accuracy, and complexity of production in monologic (Ellis \& Yuan, 2004; Foster \& Skehan, 1996; Ong \& Zhang, 2010; Skehan \& Foster, 1999; Yuan \& Ellis, 2003) and interactive tasks (Philp, Oliver, \& Mackey, 2006; Robinson, 2001), relatively little research has examined the effect of task complexity along either dimension on the production of interactional modifications such as LREs. The available research (c.f., Hardy \& Moore, 2004; Philp et al., 2006; Robinson, 2001) shows that resource-dispersing variables that alter the complexity of a task can influence the occurrence of interactional modifications. The role of these variables in tasks carried out in text chat may be even more important because of the already challenging nature of communication in this context, which lacks paralinguistic features that aid communication in face-to-face settings (Smith, 2003). However, research on the role of task complexity in communication and learning opportunities has not yet been extended to text chat. The purpose of the current study is to determine how task complexity along the resource-dispersing dimension may impact on noticing and discussion of form in group text chat interactions. Hence, the aim of this study is to uncover the extent to which task complexity may impact on text chat as a context for WLL.

Two variables were selected for the current study: task structure and language support. In the current study, high task structure (+TS) refers to the degree of structural support provided to learners during a chat session. As high task structure (+TS) serves to guide task performance, the learners' online processing burden may be reduced. In contrast, the low task structure (-TS) leaves the sequencing of discourse processes open, which requires increased demand on online processing to determine the procedures for completing the task and communicating meaning. According to the Cognition Hypothesis (Robinson, 2001, 2005), a task with low structural support (-TS) would be considered more complex because it demands a higher degree of simultaneous allocation of cognitive resources. This is predicted to result in more interactional modifications.

Language support, the second variable examined in this study, was included to reflect pedagogical practices common to the instructional site. While not specifically mentioned in the Triadic Componential Framework proposed by Robinson (2007b), the pre-task language support activities used in this study were conceptualized as similar to language-oriented pre-task planning. The main difference is that unlike pre-task planning, these activities did not involve access to the target task. However, care was taken to ensure that the activities gave learners opportunities to prepare for their language use during the task, similar to language-oriented pre-task planning. This was done by requiring learners to analyze samples of conversations on the task topic and to produce language similar to that required by the task (see Appendix A). Therefore, language support was considered similar to language-oriented pretask planning, and predicted to have similar effects on language production. No language support (-LS) was considered more complex because it pushes learners to allocate their cognitive resources simultaneously to meaning and language form. This increases demands on learner attentional resources, which is predicted in the Cognition Hypothesis to lead to greater occurrence of interactional modification.

The research questions for the current study are:

Research Question 1: Does increasing complexity through decreasing task structure increase the quantity of language related episodes (LREs) in group text chat tasks?

Research Question 2: Does increasing complexity through decreasing language support increase the quantity of language related episodes (LREs) in group text chat tasks?

\section{Method}

\section{Participants}

The study took place at a technical university in Malaysia specialising in engineering. Ninety-six second-year electrical engineering undergraduates were randomly selected to participate in this study. They were enrolled in a compulsory course on English for Professional Communication, and had studied English as a group in their previous 
Table 1

Learner characteristics.

Characteristic

Gender

Male

Age

Female

L1 background

Mean

21.8 years

Range

20-24 years

Malay

Tamil

Others

semesters at university and as a compulsory subject in primary and secondary school. Their English language proficiency was at an intermediate level as indicated by their English grades for the national examination in which most had obtained a grade of 4-6 on a nine-point scale. Their English courses were not primarily task-based; however, they were conducted in computer language learning laboratories. All participants were experienced users of CMC. Table 1 summarises the characteristics of the learners.

The task

The task used in the study was a 45-minute interactive problem-solving task which required the learners to role play engineers in a multinational company who were meeting on-line to decide what type of electrical engineering software the company should adopt. Each learner had their own detailed software option to propose. They were instructed to compare and contrast the appropriate software and to reach consensus on the best software to be purchased based on a set of criteria (see Appendix B). By the end of the task each learner was expected to have filled in a sheet with their recommendations on the ranking of the software which was to be sent to the CEO. Learners were given 40 minutes to complete the task.

\section{Task structure}

Written instructions on how to perform the task and information on one software option with its technical description were given to each learner. Learners in the low task structure ( $-\mathrm{TS}$ ) version of the task were given no further guidance on how to complete the task. Learners in the high task structure (+TS) condition were given a worksheet containing a comparison table which they were required to fill in as they discussed each software option (see Appendix C). The worksheet provided a framework for discussing the software.

\section{Language support}

In the language support (+LS) condition, learners worked through a pre-task, computer-based, form-focused activity which targeted either auxiliary or modal verbs (half the learners received the auxiliary verbs exercise and the other half the modal verbs exercise). The activity was in three parts. The first part focused on raising awareness of the targeted linguistic items through a dialogue seeded with the target form which the learners were required to underline. This dialogue was based on speakers discussing different types of engineering software. The second part included an explicit metalinguistic explanation of the forms and a short multiple-choice grammar exercise. The third section was a blank-filling exercise that required learners to use the targeted forms in sentences comparing software.

The learners received immediate feedback after completing each section and the instructor summarised important points about target forms at the end of the activity. A brief guide to auxiliary and modal verbs was also available on screen during the task performance. Learners in the no-learning support ( - LS) condition simply completed the task without any pre-task activity. 
Table 2

Task conditions.

\begin{tabular}{lll}
\hline & Low task structure (-TS) & High task structure (+TS) \\
\hline No language support & G1 & G2 \\
(-LS) & $n=24$ & $n=24$ \\
With language support & G3 & G4 \\
$(+$ LS $)$ & $n=24$ & $n=24$ \\
\hline
\end{tabular}

\section{Design}

The two options (+/-) for each of the two task conditions led to the four task implementation conditions illustrated in Table 2. Learners were randomly assigned to one of the four conditions. The 24 learners in each condition were divided into six teams, with four learners in each team.

The learners were connected to each other in a team chat room by networked computers. New chat messages are added at the bottom of a scrolling screen, allowing the interlocutors to view messages as they are delivered. As learners were in English language classes they were aware of the expectation to use English and were reminded to do so prior to the sessions. Team members were seated far enough apart to ensure they could not directly speak to each other during the chat session and were not told who the other team members were (each learner used a pseudonym).

\section{Data collection}

The instructor and the researcher monitored and captured each learner's screen from the main terminal using the classroom management systems. Following each chat session, the chat exchanges were saved in log files, which served as the primary data source for this study. Chapelle $(2003$, p. 98$)$ refers to this as "process data", which is naturally divided by an individual's turn as illustrated in example 1 (all examples are from the data set).

Group interviews were also carried out in a face to face setting with three teams from each condition to obtain information on their perceptions of the task performance and of the value of task-based text chat for language learning.

\section{Coding}

Swain and Lapkin (2001) define an LRE as any part of a dialogue where learners talk about, question, or correct the language produced. Following their definition, LREs in the current study were defined and coded into two categories:

1. LREs on meaning - Discourse in which learners talk about or ask or question implicitly or explicitly their own or others use of meaning, content, or lexical items.

2. LREs on form - Discourse in which learners talk about or ask or question implicitly or explicitly their own or others use of linguistics or grammatical items.

Examples 2 and 3 illustrate LREs on meaning and form.

Inter-rater measures were calculated based on agreement between two raters, one of whom was the first author. The second rater coded $25 \%$ of the data and $90 \%$ agreement was reached. This was considered sufficient for the first author

Text chat.

\begin{tabular}{lll}
\hline Line & Learner & Chat exchange \\
\hline 1 & Lisa & i have the best ever software in the world \\
2 & Bo & can you elaborate \\
3 & Lisa & Yeah \\
4 & Kieran & what is the software? \\
5 & Lisa & of course \\
6 & Adam & i eager to know.... \\
7 & Lisa & it is maxplus, 2 \\
\hline
\end{tabular}


Example 2

LRE on meaning.

\begin{tabular}{lll}
\hline Line & Learner & Chat exchange \\
\hline 1 & Amet & Can it work in both platforms? \\
2 & Azim & platforms? what? \\
3 & Maria & ya rick, what is that mean? \\
4 & Amet & i mean linux and windows operating systmes \\
5 & Azim & oic. no only windows \\
6 & San & Oooooo \\
\hline
\end{tabular}

Example 3

LRE on form.

\begin{tabular}{lll}
\hline Line & Learner & Chat exchange \\
\hline 1 & Yasmin & madi... hani will explains first ok \\
2 & Hani & kk thanks \\
3 & Yasmin & b quick hani \\
4 & Madi & wiat! after will, we canot put s \\
5 & Hani & what madi? \\
6 & Jack & *yasmin- she will explain- \\
7 & Madi & will explain - don't pout s \\
8 & Yasmin & oh ok ok. quick! \\
\hline
\end{tabular}

to code the remaining data. Interview transcripts were read by the main researcher to determine trends in responses. These were used to help interpret the quantitative results presented below.

\section{Analysis}

A two-way MANOVA analysis was carried out to analyze the effect of task structure and language support on LREs for form and meaning. Because LREs are collaborative, analysis was based on LREs per team.

\section{Results}

Overall, 180 instances of LRES occurred in the data of which 106 focused on form and 74 on meaning. For each treatment condition, means and standard deviations were calculated based on the number of groups (six groups per cell). These are reported in Table 3. The highest occurrence of LREs was apparent in the (+LS/+TS) group, and the lowest occurrence evident in the (-LS/-TS) group. MANOVA tests results are reported in Table 4.

The MANOVA test using the Hotelling's Trace criteria was statistically significant $(p<0.0001)$ for both main effects. The effect size for task structure was medium $\left(\eta_{\mathrm{p}}{ }^{2}=0.66\right)$, while the effect size for language support was large $\left(\eta_{\mathrm{p}}{ }^{2}=0.88\right)$. This indicates that follow-up analyses of between-subjects effects (i.e. the effects of task structure and language support on the dependent variables) were necessary. However, the interaction between task structure and language support was not significant, $(p=0.471)^{1}$, indicating that neither variable influenced the effect of the other.

\section{Language-related episodes on meaning}

Analysis of between-subjects effects on the LREs on meaning is presented in Table 5. The univariate betweensubjects test shows that task structure and language support were significantly related to the LREs on meaning.

\footnotetext{
${ }^{1}$ Note that the observed power of this test is 0.16 which is well below 0.80 . Therefore, the possibility of type II error is sufficiently low to be confident in this judgement.
} 
Table 3

Language-related episodes (LREs): descriptive statistics.

\begin{tabular}{|c|c|c|c|c|c|}
\hline & & $-\mathrm{LS}-\mathrm{TS}$ & $-\mathrm{LS}+\mathrm{TS}$ & $+\mathrm{LS}-\mathrm{TS}$ & $+\mathrm{LS}+\mathrm{TS}$ \\
\hline \multirow[t]{3}{*}{ LREs Meaning } & Total & 9 & 15 & 20 & 30 \\
\hline & Mean & 1.50 & 2.50 & 3.33 & 5.00 \\
\hline & SD & .55 & .55 & .52 & .89 \\
\hline \multirow[t]{3}{*}{ LREs Form } & Total & 13 & 21 & 33 & 39 \\
\hline & Mean & 2.17 & 3.50 & 5.50 & 6.50 \\
\hline & SD & .75 & .55 & 1.38 & 1.05 \\
\hline
\end{tabular}

Table 4

Language-related episodes: multivariate tests.

\begin{tabular}{lllllllll}
\hline Multivariate test $^{\mathrm{c}}$ & & & & & & \\
\hline & & Value & $F$ & $\begin{array}{l}\text { Hypothesis } \\
d f\end{array}$ & $\begin{array}{l}\text { Error } \\
d f\end{array}$ & $p$ & $\eta_{\mathrm{p}}{ }^{2}$ & Observed power $^{\mathrm{a}}$ \\
\hline TS & Hotelling's Trace & 1.98 & $18.84^{\mathrm{b}}$ & 2.00 & 19.00 & $<0.0001$ & 0.66 & 1.00 \\
LS & Hotelling's Trace & 7.70 & $73.20^{\mathrm{b}}$ & 2.00 & 19.00 & $<0.0001$ & 0.88 & 1.00 \\
TS*LS & Hotelling's Trace & 0.08 & 0.78 & 2.00 & 19.00 & 0.471 & 0.08 & 0.16 \\
\hline
\end{tabular}

Note: $* p \leq 0.05$.

a Computed using alpha $=0.05$.

${ }^{\mathrm{b}}$ Exact statistic.

${ }^{c}$ Design: intercept + TS + LS + TS*LS.

Table 5

Language-related episodes on meaning: test of between-subjects effects.

\begin{tabular}{llllllll}
\hline Test of between-subjects effects & & & & \\
\hline & Type III & $d f$ & Mean square & $F$ & $P$ & $\eta_{\mathrm{p}}{ }^{2}$ & Observed power $^{{ }^{2}}$ \\
& Sum of squares & & & & & & \\
\hline TS & 10.67 & 1 & 10.67 & 25.60 & $<0.0001$ & 0.56 & 1.00 \\
LS & 28.17 & 1 & 28.17 & 67.60 & $<0.0001$ & 0.77 & 1.00 \\
TS*LS & 0.67 & 1 & 0.67 & 1.60 & 0.220 & 0.07 & 0.23 \\
\hline
\end{tabular}

Note: ${ }^{*} p \leq 0.05$.

${ }^{\text {a }}$ Computed using alpha $=0.05$.

The groups in the language support (+LS) condition produced significantly more LREs on meaning $(M=4.17$, $S D=1.11)$ than the groups in the no language support $(-\mathrm{LS})$ condition $(M=2.00, S D=0.74)$. This was quite a large difference $\left(\eta_{\mathrm{p}}{ }^{2}=0.77\right)$. Meanwhile, the high task structure (+TS) groups produced significantly more LREs on meaning $(M=3.75, S D=1.48)$ than the low task structure $(-\mathrm{TS})$ groups $(M=2.42, S D=1.08)$. This was a medium difference $\left(\eta_{\mathrm{p}}^{2}=0.56\right)$. Fig. 1 displays the differences between the four groups.

\section{Language-related episodes on form}

The univariate between-subjects test shows that task structure and language support were significantly related to the LREs on form. This is presented in Table 6.

Fig. 2 below shows the mean difference between the four groups. Similar to the results of LREs on meaning, the language support (+LS) groups had significantly more LREs on form $(M=6.00, S D=1.28)$ than the no language support $(-\mathrm{LS})$ groups, $(M=2.83, S D=0.94)$. This was quite a large difference $\left(\eta_{\mathrm{p}}{ }^{2}=0.76\right)$. In the task structure scores, the high task structure (+TS) groups produced significantly more LREs on form $(M=5.00, S D=1.76)$ than low task structure $(-\mathrm{TS})$ groups $(M=3.83, S D=2.04)$. Although significant, the effect size was quite small $\left(\eta_{\mathrm{p}}{ }^{2}=0.30\right)$. 


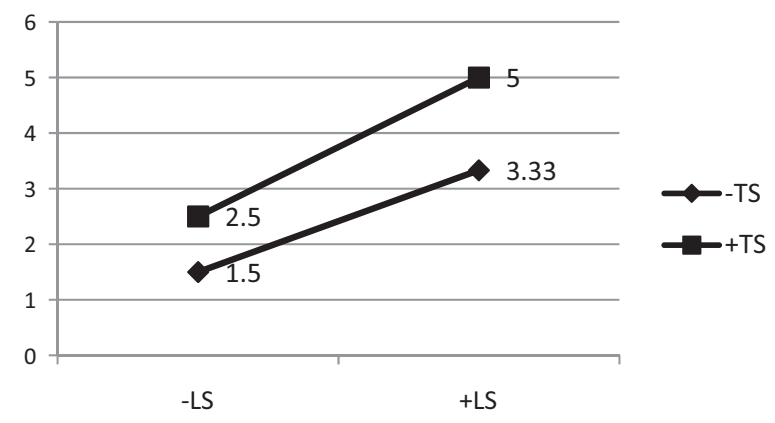

Fig. 1. Mean number of LREs on meaning.

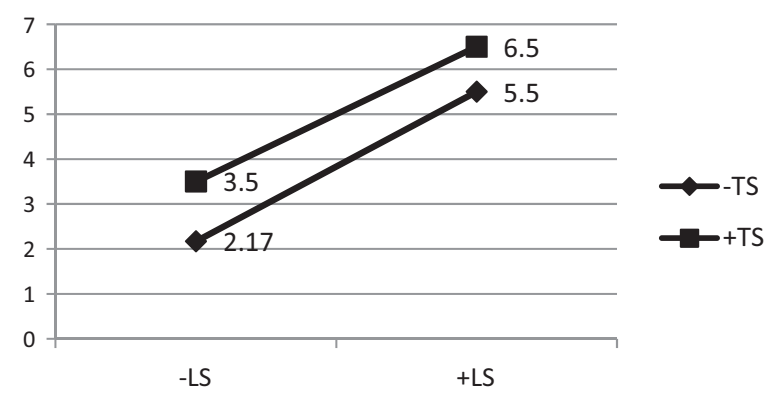

Fig. 2. Mean number of LREs on form.

\section{Discussion}

According to Robinson (2007a), the cognitive demands of a task can influence learner language production and task engagement. The current study was designed to examine this claim in the context of engineering learners performing a text chat-based task. The study focused on whether two implementation features, task structure and language support, would influence the occurrence of LREs in task-based text chat. The findings indicate that for both implementation variables, increasing complexity led to decreased interactional modifications (measured through LREs), contrary to predictions derived from Robinson's Cognitive Hypothesis. Rather, decreasing task complexity through either increasing task structure or providing language support led to more LREs. This suggests that, for interactive tasks in text chat, greater attention to language meaning and form may be more likely when task complexity is lowered. Decreasing task complexity through task implementation variables may enhance the effectiveness of a text chat task as a context for WLL. In this section, specific findings for each research question are discussed. Information from the qualitative interviews is included to contextualize and interpret the findings.

Research Question 1: Does increasing complexity through decreasing task structure increase the quantity of language related episodes (LREs) in group text chat tasks?

For both LREs on meaning and form, this study showed that decreasing task complexity through increasing task structure led to more attention to form. Evidence from the interviews and transcripts also suggests that the structural support provided to learners in the +TS condition eased their online processing demands, allowing learners to focus on discussing meaning and form, rather than managing their performance. The following extract ${ }^{2}$ provides an example of an LRE in the +TS condition. It shows how the learners' performance was clearly structured using the +TS worksheet. It also shows how learners took this opportunity to modify the problematic utterances that they had noticed.

\footnotetext{
${ }^{2}$ Pseudonyms are used in all extracts.
} 
Table 6

Language-related episodes on form: test of between-subjects effects.

\begin{tabular}{lllcrcrc}
\hline Test of between-subjects effects & & & & & \\
\hline & Type III & $d f$ & Mean square & $F$ & $P$ & $\eta_{\mathrm{p}}{ }^{2}$ & Observed power $^{\mathrm{a}}$ \\
& Sum of squares & & & & & & \\
\hline TS & 8.17 & 1 & 8.17 & 8.45 & 0.01 & 0.30 & 0.79 \\
LS & 60.17 & 1 & 60.17 & 62.24 & $<0.0001$ & 0.76 & 1.00 \\
TS*LS & 0.17 & 1 & 0.17 & 0.17 & 0.682 & 0.01 & 0.07 \\
\hline
\end{tabular}

Note: ${ }^{*} p \leq 0.05$.

${ }^{\text {a }}$ Computed using alpha $=0.05$.

\section{(1)}

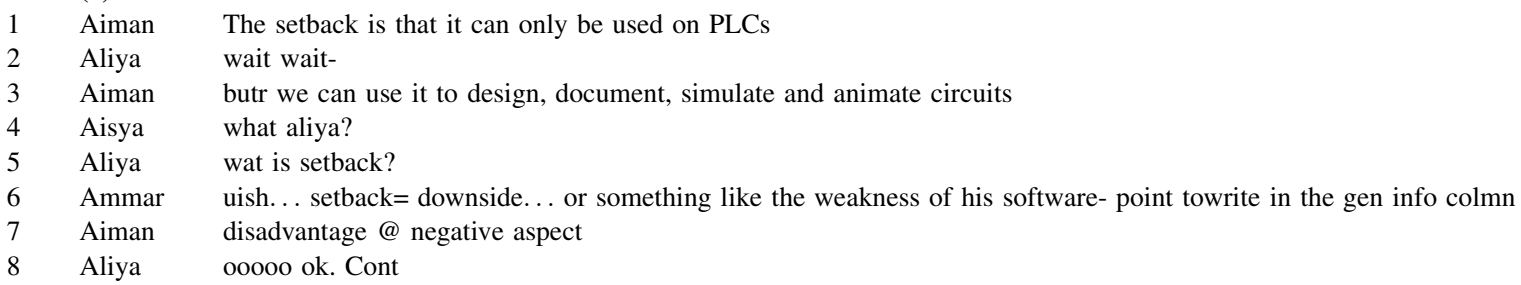

In line five Aliya shows she does not understand the word 'setback', which was used by Aiman in line one. In lines six and seven, Ammar and Aiman respond to Aliya's question by modifying Aiman's prior output, elaborating on the output, and making explicit reference to the information in the +TS material. (Ammar's and Aiman's responses are likely composed simultaneously). In the interviews, one of the participants in the +TS condition commented that:

(3)

Usually, when I chat with my friends it is very difficult to organise our conversation. Everybody wants to talk at the same time. Sometimes, you forgot the previous topic of discussion. However, when we have sheet B, I can see that everyone knows whose turn should be next. We can wait until the person finishes his/her explanation. So, it is easier for us to track our conversation and we can pay attention to our language, especially our grammar.

In contrast, in the task without structural support (-TS), learners had to devote more attention to managing their performance as exemplified in Extract 2, which is typical of task performance in the -TS condition.

(2)

1 Pian bcoz my software has a readable source code-

2 Lan my software is compatible for linux and windows

3 Pian is easy for troubleshooting- can do ourselevs

4 Din Mmine is xpensve- must renewal the license!

$5 \mathrm{Ri}$ oowhhh pls people- xplain your software using the specific criteria- will b easier for us to compare! and use correct grammar pls!

6 Lan ???

7 Din pls everybody...... one by one okay

8 Pian $\mathrm{Ok}$

9 Lan can we start again?

10 Din no we dontt have time

$11 \mathrm{Ri}$ owhhh iam confised now. canwe start again

12 Pian listento me guys. i think the idea is good- westart again. one by one

13 Din no we have, 20minutes only

In lines one to four, three learners describe their software based on the different aspects: Pian (starting in line one and ending in line three) describes the practicality of his software; Lan (line two) explains the compatibility of his software; and Din (line four) talks about the cost of his software. As implied in Ri's statement (line five), the organisation of the information presented by each of them was muddled, which caused difficulty in making comparisons. Ri also reminds his teammates to use correct grammar. However, nobody responds to his reminder, instead the conversation continues with learners discussing the need to re-start the discussion (lines nine, 11, and 12). 
During the interview with this team, they expressed their frustration at the difficulty of managing the conversation's flow. This may have prevented them from noticing Ri's reminder about using correct grammar and Din's ungrammatical used of 'renewal' in line four. One of the learners from the -TS condition expressed frustration over the difficulty in managing the task performance, and noted his perception that this impeded his ability to focus on form: (4)

You see how difficult it is to match the software description of your teammates with yours. For example, every time I receive a new message about one of my teammates' software, I have to scroll up to see the previous messages from the others' too. I'm sure that the four of us have the three criteria to discuss- utilisation, practicality and cost- but the information is just all over the place. It takes a lot of time and it is frustrating when I couldn't find the match. It is more frustrating when I don't correct my grammatical errors because I am occupied with looking for the match!

It appears that increasing the task complexity by removing structural support diverted learner attention from their use of language in the task. In contrast, learners reported that the low complexity implementation condition (i.e., adding structural support) provided them with more opportunities to attend to the language they were producing in their writing. The quantitative analysis shows that this led to greater production of LREs through which the learners provided feedback to one another on aspects of their language use. Prior research on feedback and second language writing suggests a strong link between attention to language form and subsequent language learning (c.f., Adams, 2003; Sachs \& Polio, 2007). Indeed, as Manchón (2011) points out, the foundation of the WLL perspective on writing is that through opportunities to attend to form in writing, learners make form-meaning connections that allow them to develop and refine their L2 knowledge. In summary, the data suggests that providing more task structure enhanced the effectiveness of this computer-based task as an opportunity to learn language through writing.

Research Question 2: Does increasing complexity through decreasing language support increase the quantity of language related episodes (LREs) in group text chat tasks?

As with task structure, the findings of the current study revealed that for both LREs on meaning and on form, more interactional modifications were produced in the $+\mathrm{LS}$ condition. In other words, the interactive simple task (+LS) encouraged more LREs than the interactive complex task (-LS).

It should be noted that these findings may be related to the way that language support was operationalized in the current study; i.e., in terms of attention to specific linguistic forms, and that language focused exercises may influence production differently to pre-task planning time. While this is not as canonical a test of the Cognition Hypothesis as the use of task structure, it sheds light on a common use of language practice with tasks in the classroom. The use of language practice as a pre-task activity in this study seemed to promote learner consciousness of their language production, and may have increased the likelihood of noticing gaps in expression, resulting in more opportunities to engage in discussion on language issues and receive feedback regarding those problems. Examination of the chat transcript supports this interpretation. The following extract (extract 5) is typical of discourse in the +LS condition.

$\begin{array}{ll}\text { (5) } & \\ \text { Zul } & \text { oRcad can performs well } \\ \text { Salim } & \text { meaning/?. } \\ \text { Adi } & \text { ZUL- *can perform } \\ \text { Zaza } & ? ? ? \\ \text { Zul } & \text { orcad *can perform* well. } \\ \text { Zaza } & \text { owh grammar } \\ \text { Salim } & \text { use correct english every } 1\end{array}$

Adi notices Zul's non-target like use of a modal verb construction (one of the target forms for the language support) and recasts it (with the * for emphasis) in line three. In line five, Zul modifies his output. In line six and seven Zaza and Salim explicitly recognize the grammar focus before the group moves on. During the interview with this team, Adi claimed that he was conscious of his and other teammates' language production, crediting the language activity completed prior to the task performance and the language support material received during the task. Zul pointed out that he only noticed the error he made when Adi pointed it out. Immediately after, he referred to the language notes and modified his language. 
There was clearly less focus on monitoring language production in the -LS condition. As the quantitative analysis showed, there was less discussion on form and little feedback on the language output. From post-task interviews, it seemed that participants noticed errors in the discourse, but chose not to discuss them. One learner from the -LS condition notes:

(6)

Although both Asha and Na do not use correct grammar, everyone understands what is going on. So, I don't think I need to talk about the error or correct it.

This suggests that the completion of pre-task language support activities may have worked to reframe learner understanding of the task. Learners who participated in language focused activities may have been more likely to consider focus on language use a purpose of the task. Without this focus, learners may not have considered monitoring language to be an important aspect of the task, missing opportunities to focus on language production and help each other to strengthen their target language knowledge (c.f., Fortune, 2005). Additionally, language support seems to have enhanced learner noticing of problematic output. This points to an important role for pre-task language activities if a goal of the writing task is language use to promote language learning. These findings reflect those of Leeser (2004), who also found that pre-task language focus promoted the use of LREs in dyadic interaction. As noted above, engagement in LREs is a form of evidence that learners are engaging in the cognitive processing that allows for WLL. Adams and Ross-Feldman (2008) have pointed out that focus on form during writing tasks may be more beneficial in writing than in oral interaction tasks because writing tasks allow learners greater time to process and discuss form. While text chat occurs rapidly in real time like oral communication, other characteristics of text chat, notably the visual record of communication through which learners can scroll backwards and forwards, may allow for discussion of and reflection on linguistic form without taxing memory capacity. Pre-teaching of linguistic form to promote the use of LREs in text chat may therefore lead to greater opportunities for learning language during the process of writing.

It should be noted, however, that the provision of useful language models may have reduced the cognitive demands of the task, and that this may have allowed learners to monitor their output and engage in more interactional modifications. The findings of this study do not support Robinson's predictions about the effect of increasing task complexity in interactively complex tasks.

However, these findings do point to ways of promoting learning opportunities in text chat tasks. Interestingly, the task implementation factors examined here increased both LREs on meaning and LREs on form. Prior research on writing has reported that problems in lexical features are relatively easier to notice and express than grammatical ones (Hanaoka, 2007). Similarly, lexical negotiation has been found to be the main trigger in text chat (Blake, 2000; Cheon, 2003). However, in the current study the descriptive statistics revealed that task performance under both the +TS condition and the +LS condition promoted more LREs on form than meaning.

It is possible that decreasing task complexity may have freed up attentional capacity and thus allowed greater attention to form. For learners in the +LS condition, the grammar-focused nature of the language support activities may have oriented them to talk about grammatical features more than lexical items during their task performance. In Leeser's (2004) and Fortune's (2005) studies, the learners were also directed to the use of well-formed structures prior to task performance and this heightened their attention to language form.

Additionally, the relatively high occurrence of LREs on grammar may have been related to the learners' familiarity with the content of the task. The topic of engineering software was related to the students' engineering studies and so the content and technical vocabulary required for the task was familiar. With the lexical difficulties kept to a minimum, learner attention may have been available to focus more on discussing problematic grammatical items. These results reflect Alegría de la Colina and García Mayo's (2007) findings that use of a task relevant to the learners' future profession may have led to greater attention to grammatical forms than lexical items that were familiar to them. In other words, using a task on a familiar topic may have allowed for attentional trade-off effects, as proposed by Skehan (1998).

While there was more focus on grammar in this than prior studies of task-based text chat, overall the occurrence of LREs was relatively low. It is possible that the online chat transcripts failed to capture important off-line data such as self-correction (cf., Smith, 2008). The monitoring of output provided collaboratively in spoken discourse may in part be taken over by the composing process in text chat. Text chat transcripts therefore may not show all instances of monitoring or noticing, or fully reflect the learning opportunities within text chat tasks. 
According to a number of participants, the written modality of text chat enabled them to compose and delete their writing before posting the messages. Additionally, the text messages meant learners could scroll backward and forward, which enabled them to digest information before responding. Comments from the interviews indicated that scrolling backward enabled learners to make sense of unknown lexical items that caused miscommunication. While this indicates a high level of awareness of language, it may have led to a lower rate of LREs in the data. In addition, some learners reported that they chose to wait before posting their response to other messages. By doing so, they claimed they had time to internalise the meaning, and think about the most appropriate language expression to use. Therefore, instead of talking about or discussing the language they or others produced, they opted for not verbalizing their thoughts on screen. These comments from learners in the study suggest that text chat is a valuable medium for WLL in two closely related ways. First, text chat gave learners opportunities to focus on language because it allowed for off-line composing and editing. This may have freed attentional resources to focus on the accuracy of linguistic output. Secondly, text chat gave learners opportunities to collaboratively construct the discourse, providing one another with immediate responses to questions about language, corrections, and other instances of focus on form. Different to pen and paper writing, text chat allowed for discussion of the accuracy of the composed messages during, rather than after, the composition process.

\section{Conclusion}

This study has evaluated the impact of two task implementation features on text chat as a WLL context by focusing on how these factors impact on opportunities to engage in discussion of linguistic form. The results indicate that learners may be more likely to attend to linguistic accuracy through LREs in text chat writing if pre-task language support is available and if the performance of the task is guided so as to reduce the procedural demands of the task. It is hypothesized that in both cases, the effect of these implementation variables is to free attentional resources needed for learners to focus not just on communicating meaning but also to focus on how they express that meaning in a computer-mediated writing environment. While the results of the current study seem to contradict predictions derived from the Cognitive Hypothesis concerning the effect of cognitive complexity on language performance, they also show ways that writing tasks may be implemented to help learners make the most use of text chat communication as a collaborative writing context that promotes opportunities for language learning.

Overall, the findings of this study highlight the potential of text chat as a context for WLL. While the occurrence of overt focus on form was somewhat limited, the high proportion of LREs directed at form suggests that interactive text chat may be a potential site for learners to engage in writing that allows them to process language in ways that promote refinement of their knowledge of L2 form. Future research could consider the contributions of both online text chat and offline editing to present a fuller picture of both the individual and collaborative focus on form that occurs in text chat. In addition, further research could monitor focus on form and language use over time to better understand how discrete learning opportunities in text chat translate into language knowledge gained through engagement in writing.

\section{Appendix A. Language support material (+LS)}

\section{Activity 1: Awareness.}

The following is a dialogue between two friends, Evan and John, who are discussing purchasing the software they will need to use for a course on "Technical Diagramming and Drafting Solutions" next week. It is late at night in the weekend, and the discussion is carried out via text chat.

Instructions: Read the following and underline the auxiliary verbs.

Evan:Hi John! Are you browsing the net for the software to be used in EEE 3113 ?

John: Yup. Have you found anything?

Evan:I've found Zesty Tech. \& Evo (ZTE). It has thousands of built-in, discipline specific "Wonderful Contours" objects for all technical diagramming and drafting applications.

John: How does "Wonderful Contours" work?

Evan:More than, 10,000 "Wonderful Contours" objects are organised into task-specific Subject Voyager catalogues. It enables the users to have immediate access to the content.

John: Could you explain further?

(After completing Activity 1, students received immediate feedback electronically.) 
Activity 2:Explicit language focus.

Auxiliary verbs (sometimes known as helping verbs) are verbs that are used to assist the main verb. Three most common auxiliary verbs are be, do and have.

\begin{tabular}{llll}
\hline & Be & Do & Have \\
\hline I & Am/was & Do/did & Have/had \\
You & Are/were & Do/did & Have/had \\
He/she/it & Is/was & Does/did & Has/had \\
We & Are/were & Do/did & Have/had \\
They & Are/were & Do/did & Have/had \\
\hline
\end{tabular}

\section{Activity 3: Production.}

The following is a dialogue between three friends who are doing a Bachelor's degree in Electrical and Electronic Engineering. Lina, Dave and Mike are discussing purchasing the software they will need to use for a course on "Electronic Circuits" next semester. Since this is a semester break, the discussion is done via text chat as everybody is in his/her hometown.

Instruction: Complete the dialogue with the appropriate auxiliary verbs.

\begin{tabular}{|c|c|}
\hline Lina: & Which software have you found (have, find) for the "Electronic Circuits" course next semester? \\
\hline Dave: & My suggestion would be GeniusBoardCircuit. Have you heard (have, hear) about it? \\
\hline Mike: & Yup, but it is quite expensive, isn't it? \\
\hline Lina: & Let's not talk about the price first. We should find software which is user-friendly. \\
\hline Dave: & $\begin{array}{l}\text { The most important thing about GeniusBoardCircuit is that a simulated trainer is included (be, include). So, } \\
\text { we can still continue doing our work even if our trainers are not available. }\end{array}$ \\
\hline
\end{tabular}

(After completing Activity 3, students received immediate feedback electronically.)

\section{Appendix B. Task}

The following is the sample of the task instruction received by student A in all conditions. In and that all are based at different locations worldwide. They have been asked by the CEO to select an optimal software package for their companies electrical designs, simulations, and analyses. Given a software description (each group member has a different software package), this task Student A has to promote $\operatorname{OrCAD}$. Note that each student in a team (four students in a team) received different type of software. They are informed that they are electrical engineers at a multinational company. They are tasked with communicating together online to collaboratively determine which is best the software for their company.

\section{Your software.}

OrCAD has the following technical descriptions:

- Core design tasks: Schematic and VHDL-based design entry, FPGA and CPLD design synthesis; digital, analog, and mixed-signal simulation and printed circuit board layout

- The online demo provides all the features and functionality of the actual software, 10am-3pm online helpdesk available. Purchase comes with comprehensive manual written in more than, 10 languages

- Compatible with either Microsoft or Linux operating system

- Less time spent on the details of tool integration, devising workarounds, and manually entering data to keep files in sync

- RM 2, 500 for, 10 licenses 


\section{Appendix C. Task structure material (+TS)}

\begin{tabular}{|l|l|l|l|l|}
\hline Criteria & $\begin{array}{l}\text { General } \\
\text { information }\end{array}$ & Practicality & Utilization & Cost \\
\hline OrCAD & & & & \\
\hline MATLAB & & & & \\
\hline $\begin{array}{l}\text { Automation } \\
\text { Studio }\end{array}$ & & & & \\
\hline MAXplus II & & & & \\
\hline Points & & & & \\
\hline
\end{tabular}

\section{References}

Ackerman, J. M. (1993). The promise of writing to learn. Written Communication, 10, 334-370.

Adams, R. (2003). L2 output, reformulation, and noticing: Implications for IL development. Language Teaching Research, 7(3), 347-376.

Adams, R. (2006). L2 tasks and orientation to form: A role for modality? ITL-International Journal of Applied Linguistics, 152, 7-34.

Adams, R. (2007). Do second language learners benefit from interacting with each other? In A. Mackey (Ed.), Conversational interaction in second language acquisition: A collection of empirical studies (pp. 29-51). Oxford: Oxford University Press.

Adams, R., \& Ross-Feldman, L. (2008). Does writing influence learner attention to form? In D. Belcher \& A. Hirvela (Eds.), The oral/literate connection: Perspectives on L2 speaking/writing connections (pp. 243-267). Ann Arbor, MI: University of Michigan Press.

Alegría de la Colina, A., \& García Mayo, M. P. (2007). Attention to form across collaborative tasks by low proficiency learners in an EFL setting. In M. P. García Mayo (Ed.), Investigating tasks in formal language learning (pp. 91-116). Clevedon: Multilingual Matters.

Anderson, T., \& Elloumi, F. (2004). Theory and practice of online learning. Athabasca, Canada: Athabasca University.

Applebee, A. (1981). Writing in the secondary school: English and the content areas (Research Rep. No. 21). Urbana, IL: National Council of Teachers of English.

Belz, J. A., \& Müller-Hartmann, A. (2003). Teachers as intercultural learners: Negotiating German-American telecollaboration along the institutional fault line. The Modern Language Journal, 87(1), 71-89.

Blake, R. (2000). Computer mediated communication. A window on L2 Spanish interlanguage. Language Learning \& Technology, 4(1), $120-136$.

Blake, R. (2005). Bimodal CMC: The glue of language learning at a distance. CALICO, 22(3), 497-511.

Blake, R. (2007). New trends in using technology in the language curriculum. Annual Review of Applied Linguistics, $27,76-97$.

Chapelle, C. (2003). English language learning and technology. Philadelphia: John Benjamin.

Cheon, H. (2003). The viability of computer mediated communication in the Korean secondary EFL classroom. Asian EFL Journal 5(1).

Cumming, A. (1990). Metalinguistic and ideational thinking in second language composing. Written Communication, 7, $482-511$.

Cumming, A. (2011). Preface. In R. M. Manchón (Ed.), Learning-to write and writing-to-learn in an additional language (pp. vii-x). Amsterdam: John Benjamins.

Ellis, R. (2003). Task-based language teaching and learning. Oxford: Oxford University Press.

Ellis, R., \& Yuan, F. (2004). The effects of planning on fluency, complexity, and accuracy in second language narrative writing. Studies in Second Language Acquisition, 26(1), 59-84.

Emde, S., Schneider, J., \& Kötter, M. (2001). Technically speaking: Transforming language learning through virtual learning environment. The Modern Language Journal, 85(2), 210-225.

Fortune, A. (2005). Learners' use of metalanguage in collaborative form-focused L2 output tasks. Language Awareness, 14(1), 21-38.

Foster, P., \& Skehan, P. (1996). The influence of planning and task type on second language performance. Studies in Second Language Acquisition, 18(3), 299-323.

Gilabert, R. (2007). The simultaneous manipulation of task complexity along planning time and (+/- Here-and-Now): Effects on L2 oral production. In M. P. Garcia Mayo (Ed.), Investigating tasks in formal language learning (pp. 44-68). Clevedon: Multilingual Matters.

González, D. (2003). Teaching and learning through chat: A taxonomy of educational chat for EFL/ESL. IAIEFL Poland: Computer Special Interest Group, 3(4), 57-69.

González-Lloret, M. (2009). "No me llames de usted, tratame de tu:: L2 address behavior development through synchronous computer-mediated communication. (Doctoral dissertation). University of Hawai'i at Manoa, Hawai'i.

Hanaoka, O. (2007). Output, noticing, and learning: An investigation into the role of spontaneous attention to form in a four-stage writing task. Language Teaching Research, 11(4), 459-479.

Hardy, I. M., \& Moore, J. L. (2004). Foreign language students' conversational negotiations in different task environments. Applied Linguistics, 25(3), 340-370.

Herring, S. C. (Ed.). (1996). Computer-mediated communication: Linguistic, social and cross-cultural perspectives. Amsterdam: John Benjamins. 
Ishii, D. (2008). Language dia-logs: Consciousness-raising through collaborative reflection. In J. Eckerth \& S. Siekmann (Eds.), Task-based language learning and teaching: Theoretical, methodological, and pedagogical perspectives (pp. 119-142). New York: Peter Lang.

Kim, I.-H., Anderson, R., Nguyen-Jahiel, K., \& Archodidou, A. (2007). Discourse patterns during children's collaborative online discussions. The Journal of the Learning Sciences, 16(3), 333-370.

Klapper, J., \& Reese, J. (2003). Reviewing the case for explicit grammar instruction in the university foreign language learning context. Language Teaching Research, 7(3), 285-314.

Kormos, J. (2011). Task complexity and linguistic and discourse features of narrative writing performance. Journal of Second Language Writing, $20(2), 148-161$.

Kuiken, F., \& Vedder, I. (2007). Task complexity and measures of linguistic performance in L2 writing. IRAL, 45(3), $261-284$.

Kuiken, F., \& Vedder, I. (2008). Cognitive task complexity and written output in Italian and French as a foreign language. Journal of Second Language Writing, 17, 48-60.

Lee, L. (2004). Learners' perspectives on networked collaborative interaction with native speakers of Spanish in the US. Language Learning \& Technology, 8(1), 83-100.

Leeser, M. (2004). Learner proficiency and focus on form during collaborative dialogue. Language Teaching Research, 8(1), 55-81.

Long, M. H., \& Crookes, G. (1992). Three approaches to task-based language teaching. TESOL Quarterly, 26(1), 27-56.

Manchón, R. M. (Ed.). (2011). Learning-to-write and writing-to-learn in an additional language. Amsterdam: John Benjamins.

Meskill, C. (2005). Triadic scaffolds: Tools for teaching English language learners with computers. Language Learning \& Technology, 9(1), 46-59.

Michel, M., Kuiken, F., \& Vedder, I. (2007). The influence of complexity in monologic versus dialogic tasks in Dutch L2. IRAL, 45(3), 241-259.

Newlands, A., Anderson, A. H., \& Mullin, J. (2003). Adapting communicative strategies to computer-mediated communication: An analysis of task performance and dialogue structure. Applied Cognitive Psychology, 17(3), 325-348.

Niu, R. (2009). Effect of task-inherent production modes on EFL learners' focus on form. Language Awareness, 18(3-4), 384-402.

Nuevo, A. (2006). Task complexity and interaction: L2 learning opportunities and development. (Doctoral dissertation). Georgetown University, Washington D.C.

Nuevo, A., Adams, R., \& Ross-Feldman, L. (2011). Task complexity, modified output, and learning in learner-learner interactions. In P. Robinson (Ed.), Second language task complexity: Researching the cognition hypothesis of language learning and performance. Amsterdam: John Benjamins. pp. 175-202.

Ong, J., \& Zhang, L. J. (2010). Effects of task complexity on the fluency and lexical complexity in EFL students' argumentative writing. Journal of Second Language Writing, 19(4), 218-233.

Ortega, L. (2009). Interaction and attention to form in L2 text-based computer-mediated communication. In A. Mackey \& C. Polio (Eds.), Multiple perspectives on interaction in second language acquisition: Second language research in honor of Susan M. Gass. New York: Taylor \& Francis.

Payne, J. S., \& Whitney, P. J. (2002). Developing L2 oral proficiency through synchronous CMC: Output, working memory, and interlanguage development. CALICO, 20(1), 7-32.

Pellettieri, J. (2000). Negotiation in cyberspace: The role of chatting in the development of grammatical competence. In M. Warschauer \& R. Kern (Eds.), Network-based language teaching: Concepts and practice (pp. 59-86). Cambridge: Cambridge University Press.

Philp, J., Oliver, R., \& Mackey, A. (2006). The impact of planning time on children's task-based interactions. System, 34(4), 547-565.

Révész, A. (2009). Task complexity, focus on form, and second language development. Studies in Second Language Acquisition, 31(3), 437-470.

Robinson, P. (2001). Task complexity, task difficulty, and task production: Exploring interactions in a componential framework. Applied Linguistics, 22(1), 27-57.

Robinson, P. (2005). Cognitive complexity and task sequencing: Studies in a Componential Framework for second language task design. IRAL, 43(1), 1-33.

Robinson, P. (2007a). Task complexity, theory of mind, and intentional reasoning: Effects on L2 speech production, interaction, uptake and perceptions of task difficulty. IRAL, 45(3), 193-213.

Robinson, P. (2007b). Criteria for grading and sequencing pedagogic tasks. In M. P. Gárcia Mayo (Ed.), Investigating tasks in formal language learning (pp. 7-27). Clevedon: Multilingual Matters.

Sachs, R., \& Polio, C. (2007). Learners' use of two types of written feedback on a L2 writing revision task. Studies in Second Language Acquisition, 29(1), 67-10010.1017/S0272263107070039.

Samuda, V., \& Bygate, M. (2008). Tasks in second language learning. London: Palgrave.

Sanders, R. (2006). A comparison of a chat room productivity: In-class versus out-of-class. CALICO, 24(1), 59-76.

Sauro, S. (2009). Computer-mediated corrective feedback and the development of L2 grammar. Language Learning \& Technology, 13(1), 96-120.

Shang, H.-F. (2007). An exploratory study of application on FL writing performance. Computer Assisted Language Learning, 20 (1), 79-96.

Shekary, M., \& Tahririan, M. H. (2006). Negotiation of meaning and noticing in text-based online chat. The Modern Language Journal, 90(4), 557573.

Skehan, P. (1998). A cognitive approach to language learning. Oxford: Oxford University Press.

Skehan, P., \& Foster, P. (1997). Task type and task processing conditions as influences on foreign language performance. Language Teaching Research, 1(3), 185-211.

Skehan, P., \& Foster, P. (1999). The influence of task structure and processing conditions on narrative retellings. Language Learning, 49, 93-120.

Smith, B. (2003). Computer-mediated negotiated interaction: An expanded model. The Modern Language Journal, 87(1), 38-57.

Smith, B. (2005). The relationship between negotiated interaction, learner uptake, and lexical acquisition in task-based computer-mediated communication. TESOL Quarterly, 39(1), 33-58.

Smith, B. (2008). Methodological hurdles in captures CMC data: The case of the missing self-repair. Language Learning \& Technology, 12(1), 85103.

Sotillo, M. S. (2005). Corrective feedback via instant messenger learning activities in NS-NNS and NNS-NNS dyads. CALICO, 22(3), 467-496. 
Storch, N. (2003). Relationships formed in dyadic interaction and opportunity for learning. International Journal of Educational Research, 37(3/4), $305-322$.

Swain, M., \& Lapkin, S. (2001). Focus on form through collaborative dialogue: exploring task effects. In M. Bygate, P. Skehan, \& M. Swain (Eds.), Researching pedagogic tasks: Second language learning, teaching, and testing (pp. 99-118). New York: Longman.

Tavakoli, P., \& Foster, P. (2008). Task design and second language performance: The effect of narrative type on learner output. Language Learning, 58(2), 439-47310.1111/j.1467-9922.2008.00446.x.

Tavakoli, P., \& Skehan, P. (2005). Strategic planning, task structure, and performance testing. In R. Ellis (Ed.), Planning and task performance in a second language (pp. 239-273). Philadelphia: John Benjamins.

Van den Branden, K., Bygate, M., \& Norris, J. M. (2009). Task-based language teaching. Philadelphia: John Benjamins.

Ware, P. D., \& Kramsch, C. (2005). Toward an intercultural stance: Teaching German and English through telecollaboration. The Modern Language Journal, 89(2), 190-205.

Warschauer, M. (1998). Researching technology in TESOL: Determinist, instrumental, and critical approaches. TESOL Quarterly, 32(4), 757-761. Williams, J. (2001). The effectiveness of spontaneous attention to form. System, 29(3), 325-340.

Yates, S. J. (1996). Oral and written linguistic aspects of computer conferencing. In S. C. Herring (Ed.), Computer-mediated communication: Linguistic, social and cross-cultural perspectives (pp. 29-46). Amsterdam: John Benjamins.

Yuan, F., \& Ellis, R. (2003). The effects of pre-task planning and on-line planning on fluency, complexity and accuracy in L2 monologic oral production. Applied Linguistics, 24(1), 1-27.

Zamel, V. (1982). Writing: The process of discovering meaning. TESOL Quarterly, 16/7, 195-209.

Nik Aloesnita Nik Mohd Alwi is a lecturer at Universiti Malaysia Pahang, Malaysia at the Centre of Modern Languages and Human Sciences. She recently completed her PhD study in Applied Linguistics at Victoria University of Wellington, New Zealand. Her research focuses on the use of taskbased language teaching in the context of computer-mediated communication in second language learning and teaching.

Rebecca Adams is a lecturer in the Department of Applied Language Studies and Linguistics at The University of Auckland. Her research focuses on the role of interactions between language learners in classroom settings on language learning.

Dr Newton is a senior lecturer in the School of Linguistics and Applied Language Studies, Victoria University of Wellington, New Zealand. He has been involved in language teaching and teacher training for more than twenty years in both New Zealand and China where he began his teaching career. His research focuses on task-based language teaching, intercultural language teaching and learning, and workplace-related intercultural pragmatics. 